\title{
AWARENESS AND PRACTICES APPLIED BY HEALTH CARE WORKERS TO ACHIEVE PATIENT SAFETY DURING PHLEBOTOMY AND ULTRASOUND BIOPSY
}

\author{
Salahuddin Balooch, Fakhra Noureen*, Abid Saeed Khan**, Ibad Ur Rehman***, Aleena Bakhtawar****, \\ Waseem Raza ${ }^{* * * * *}$
}

Combined Military Hospital Kharian/National University of Medical Sciences (NUMS) Pakistan, *Islamic International Medical College, Rawalpindi Pakistan, ${ }^{* *}$ Capital Development Hospital, Islamabad Pakistan, ${ }^{* * * S e r v i c e s ~ H o s p i t a l, ~ L a h o r e ~ P a k i s t a n, ~}{ }^{* * * *}$ The Children Hospital and Institute of Child Health, Lahore Pakistan, ${ }^{* * * * *}$ Tribal Areas Electric Supply Company (TESCO) Pakistan

\section{ABSTRACT}

Objective: To assess awareness and practices applied by health care workers to achieve patient safety during phlebotomy and ultrasound biopsy.

Study Design: Cross-sectional study.

Place and Duration of Study: Combined Military Hospital (CMH), Kharian, Pakistan, from Jan 2019 to Jan 2020.

Methodology: The health care providers were interrogated about their knowledge and practices regarding patient safety with respect to phlebotomy and ultrasound biopsy. The responses of participants were evaluated through correlation analysis by SPSS version 17 with $p \leq 0.05$.

Results: The results show that awareness and practice implementation for patient safety in phlebotomy and ultrasound biopsy enhance in accordance to age, education and experience $(p \leq 0.05)$. The findings of present study suggest that physicians and nurses tend to have better awareness and practices of patient safety as compared to other health care workers. Nurses showed mean value of $3.14 \pm 0.37$ for phlebotomy awareness; $3.12 \pm 0.53$ for ultrasound biopsy awareness; $3.22 \pm 0.14$ for phlebotomy practices; $2.45 \pm 0.55$ for ultrasound practices. Physicians showed mean value of $3.65 \pm 0.22$ for phlebotomy awareness, $3.66 \pm 0.36$ for phlebotomy practices, $3.77 \pm 0.24$ for ultrasound biopsy awareness and $3.24 \pm 0.53$ for ultrasound practices. However, all the health care workers included in present study showed adequate level of awareness and practice implementation.

Conclusion: The managers and co-workers need to support the health care workers' groups that tend to show lower levels of awareness and practice implantation in patient safety.

Keywords: Patient safety, Phlebotomy, Ultrasound, Ultrasound biopsy.

This is an Open Access article distributed under the terms of the Creative Commons Attribution License (http://creativecommons.org/licenses/by/4.0), which permits unrestricted use, distribution, and reproduction in any medium, provided the original work is properly cited.

\section{INTRODUCTION}

Patient safety can be regarded as deterrence of injuries to patients through proper care deliverance. It is a serious global public health concern that emphasizes on avoidance of errors through safety culture, practiced and implemented by health care professionals and respective organizations ${ }^{1}$. Health care related errors and their outcomes have become frequent with becoming known to both health care professionals and general public. Consequently, the medical mistakes have received continuous social media coverage, which has deteriorated doctor-patient trust and relationship ${ }^{2}$.

The health care quality is dependent mainly

Correspondence: Dr Salah Ud Din Balooch, Dept of Radiology, Combined Military Hospital, Kharian Pakistan

Received: 17 Aug 2020; revised received: 06 Oct 2020; accepted: 08 Oct 2020 on patient safety. Despite the scarcity of accurate estimates of problem, unsafe medical care is thought to cause disabilities and injuries in millions of patients. A part from that, thousands of people die each year owing to improper safety practices implemented by health practitioners worldwide 3 .

Patient safety culture asserts combined beliefs and values of organization's members regarding health practices and their outcomes. Such virtues are responsible of generating various behavioral norms among members that ultimately promote safety 4 . In order to achieve safety culture, it is important to understand beliefs, values, attitudes and behaviors relevant to patient safety. The discrepancies related to care quality need constant emphasis as provision of quality and safety are mandatory for an efficient and responsive health care system 5 . 
The health care systems are frequently exposed to various risks that may affect patient safety. In such circumstances, health care professionals are expected to manage the situations through their knowledgeand awareness about patient safety. The health care workers are highly held responsible to maintain safe level of patient care $^{6}$. Apart from adoption of safety skills in routine activities, physicians are expected to identify patient safety issues and incidents, work in collaboration, perform patient safety incident analysis, abstain from previous errors and help in prevention of future incidents through identification and application of appropriate actions ${ }^{7}$.

Although patient safety is required in each aspect of health care, two of the most important facets are ultrasound biopsy and phlebotomy. Ultrasound examinations are prone to various risks that vary in accordance with the invasiveness of procedure, exposure to body fluids and bacterial flora of patients. Various researchers have claimed that ultrasound procedures can result in negative outcomes ${ }^{8}$. Despite this fact, poor knowledge and practices regarding safe use of ultrasound procedures exist among the end users. Apart from that, no substantial research has been conducted to explore awareness about patient safety among health practitioners utilizing ultrasound procedures such as ultrasound biopsy ${ }^{9}$.

Phlebotomy is considered as one of the most ancient and invasive procedures in health care. It has high potential to expose health care workers to risk of blood borne pathogens such as hepatitis $\mathrm{C}$ virus (HCV), hepatitis $\mathrm{B}$ virus (HBV), and Human immunodeficiency virus (HIV ${ }^{10}$. Moreover, improper handling or collection of samples can result in contamination and haemolysis. Phlebotomy has been reported to cause unconsciousness, anxiety, fainting, pain and seizures due to poor implementation of patient safety. Most commonly reported adverse effects of phletobotomy include bruising, anatomical injuries ${ }^{1}$.

The purpose of this study is to assess patient safety awareness and practices among health care workers in terms of phlebotomy and ultrasound biopsy. Moreover, the demographics of health care workers are associated with their respective awareness and practices attributes.

\section{METHODOLOGY}

This cross-sectional, descriptive study was conducted from Jan 2019 to Jan 2020 at Combined Military Hospital (CMH), Kharian, Pakistan. The health care workers including nurses, nurse assistants, physicians and head nurses participated in present study. The participants were explained about purpose of research along with privacy, confidentiality and voluntary nature of participation in study. Questionnaires were distributed among health care workers of Combined Military Hospital, Kharian. In total, 1500 individualswere included through convenience sampling1. Out of which, only 1384 individuals filled form. However, 284 forms were discarded due to improper or incomplete filling. This resulted into a total of 1100 forms that were included in the study. The participants in present study included health care workers from Combined Military Hospital, Kharian and online respondents.

The questionnaire consisted of two sections. The first section inquired about demographic characteristics of the participants such as age, gender, work position, education, duty location, and years of experience in field. The second section interrogated about practices and awareness level of participants regarding patient safety for either phlebotomy or ultrasound biopsy. All the questions were rated against five-point Likert scale (0-Strongly disagree, 1-Disagree, 2-Neutral, 3 -Agree to 5-Strongly agree). The questionnaire was adopted from Ahmed \& Ali ${ }^{5}$ and Just ${ }^{16}$.

In order to statistically analyze the collected data, SPSS version 17 was used. The scale's reliability was checked with Cronbach's alpha. The data was presented as means and standard deviations (SD). The patient safety awareness level and practices applied by participants were associated with their background factors through Spearman correlations with $p$-value $\leq 0.05$ considered as statistically significant. 


\section{RESULTS}

Among 1100 participants, majority 360 $(32.72 \%)$ participants belonged to age range of $41-$ 50 years as shown in the table-I. On the basis of education, 438 (39.82\%) participants had acquired Master's degree. The respondents for present study were mainly females $762(69.27 \%)$ with duty location of emergency $583(53 \%)$ and experience range of 11 to 15 years 322 (29.27\%). The classifi-

Table-I: Demographics of Participants.

\begin{tabular}{|c|c|}
\hline Variables & n (\%) \\
\hline \multicolumn{2}{|l|}{ Age (years) } \\
\hline $30-35$ & $213(19.36)$ \\
\hline $36-40$ & $132(12)$ \\
\hline $41-45$ & $360(32.72)$ \\
\hline $46-50$ & $211(19.18)$ \\
\hline $51-55$ & $100(9.09)$ \\
\hline $56-60$ & $84(7.63)$ \\
\hline \multicolumn{2}{|l|}{ Education } \\
\hline Bachelors & $293(26.63)$ \\
\hline Masters & $438(39.82)$ \\
\hline Vocational / Medical school & $369(33.54)$ \\
\hline \multicolumn{2}{|l|}{ Gender } \\
\hline Male & 338 (30.73) \\
\hline Female & $762(69.27)$ \\
\hline \multicolumn{2}{|l|}{ Duty Location } \\
\hline Emergency & $583(53)$ \\
\hline In-door & $517(47)$ \\
\hline \multicolumn{2}{|l|}{ Job Position } \\
\hline Nurse & $428(38.90)$ \\
\hline Nurse head & $183(16.63)$ \\
\hline Nurse assistant & $103(9.36)$ \\
\hline Physicians & $386(35.09)$ \\
\hline \multicolumn{2}{|l|}{ Experience (years) } \\
\hline $1-5$ & $183(16.63)$ \\
\hline $6-10$ & $285(25.90)$ \\
\hline $11-15$ & $322(29.27)$ \\
\hline $16-20$ & $184(16.73)$ \\
\hline $21-25$ & $111(10.09)$ \\
\hline $26-30$ & $15(1.36)$ \\
\hline
\end{tabular}

cation on the basis of job position indicates that nurses were in majority $428(38.90 \%)$ followed by physicians 386 (35.09\%).

The table-II shows scale reliability of the questionnaire items selected for each variable. These items were chosen on the basis of previous literature. The total reliability of questionnaire was presented by Cronbach's alpha value of 0.81 , which depicted adequate reliability of the selected scale.

The table-III shows descriptive analysis for questionnaire items related to awareness and

Table-II: Scale reliability of questionnaire.

\begin{tabular}{|c|c|c|}
\hline Variables & Items & $\begin{array}{l}\text { Cronbach's } \\
\text { Alpha }\end{array}$ \\
\hline $\begin{array}{l}\text { Awareness of patient safety } \\
\text { in phlebotomy }\end{array}$ & $1-5$ & 0.71 \\
\hline $\begin{array}{l}\text { Practices of patient safety in } \\
\text { phlebotomy }\end{array}$ & $6-10$ & 0.87 \\
\hline $\begin{array}{l}\text { Awareness of patient safety } \\
\text { in ultrasound biopsy }\end{array}$ & $11-15$ & 0.88 \\
\hline $\begin{array}{l}\text { Practices of patient safety in } \\
\text { ultrasound biopsy }\end{array}$ & $16-20$ & 0.79 \\
\hline Total & $1-20$ & 0.81 \\
\hline \multicolumn{3}{|c|}{$\begin{array}{l}\text { Table-III: Awareness and practices of patient } \\
\text { safety in phlebotomy and ultrasound biopsy. }\end{array}$} \\
\hline Variables & & Mean \pm SD \\
\hline \multicolumn{3}{|c|}{ Awareness of Patient Safety in Phlebotomy } \\
\hline $\begin{array}{l}\text { Responding appropriately to } \\
\text { adverse patient reactions } \\
\text { Caring for patients with spe } \\
\text { needs } \\
\text { Sample integrity } \\
\text { Infection prevention } \\
\text { Patient care and communica }\end{array}$ & & $\begin{array}{l}2.56 \pm 0.434 \\
3.22 \pm 0.484 \\
3.11 \pm 0.245 \\
3.25 \pm 0.144 \\
2.65 \pm 0.535\end{array}$ \\
\hline \multicolumn{3}{|c|}{ Practices of Patient Safety in Phlebotomy } \\
\hline $\begin{array}{l}\text { Strict aseptic technique follo } \\
\text { Barrier precautions taken } \\
\text { Care through gloves weared } \\
\text { Two hands technique using } \\
30 \text { degrees angle } \\
\text { Phlebotomy site dressing ap }\end{array}$ & 5 to & $\begin{array}{l}1.43 \pm 0.464 \\
2.44 \pm 0.475 \\
1.64 \pm 0.258 \\
\\
2.53 \pm 0.749 \\
3.55 \pm 0.646\end{array}$ \\
\hline \multicolumn{3}{|c|}{ Awareness of Patient Safety in Ultrasound Biopsy } \\
\hline $\begin{array}{l}\text { Appropriate needle and dev } \\
\text { selection } \\
\text { Recognizing and managing } \\
\text { procedural complications } \\
\text { Screening for contraindicati } \\
\text { Use of optimal room setup } \\
\text { Performing preliminary scar }\end{array}$ & & $\begin{array}{l}2.64 \pm 0.576 \\
3.21 \pm 0.856 \\
2.55 \pm 0.387 \\
3.16 \pm 0.674 \\
2.65 \pm 0.356\end{array}$ \\
\hline \multicolumn{3}{|c|}{ Practices of Patient Safety in Ultrasound Biopsy } \\
\hline $\begin{array}{l}\text { Performing in a clean room } \\
\text { Cleansing of hands with ant } \\
\text { agent } \\
\text { Patient asepsis } \\
\text { Wearing masks and gloves } \\
\text { Discarding of used material }\end{array}$ & eptic & $\begin{array}{l}3.22 \pm 0.185 \\
2.54 \pm 0.548 \\
3.44 \pm 0.852 \\
3.55 \pm 0.521 \\
1.64 \pm 0.664\end{array}$ \\
\hline
\end{tabular}


practices of patient safety in phlebotomy and ultrasound biopsy. It is evident that participants were well aware of various attributes and practices of patient safety in phlebotomy. They consi-

Table-IV: Association of variables with participant groups.

\begin{tabular}{l|c|c}
\hline $\begin{array}{l}\text { Variables and } \\
\text { Participant Groups }\end{array}$ & Mean \pm SD & $p$-value \\
\hline Awareness of Patient Safety in Phlebotomy \\
\hline Nurses & $3.14 \pm 0.37$ & \\
Nurse heads & $2.54 \pm 0.25$ & $<0.001^{*}$ \\
Nurse assistants & $2.13 \pm 0.53$ & \\
Physicians & $3.65 \pm 0.22$ & \\
\hline \multicolumn{3}{l|}{ Practices of Patient Safety in Phlebotomy } \\
\hline Nurses & $3.22 \pm 0.14$ & \\
Nurse heads & $3.14 \pm 0.54$ & $<0.001^{*}$ \\
Nurse assistants & $2.35 \pm 0.75$ & \\
Physicians & $3.66 \pm 0.36$ & \\
\hline Awareness of Patient Safety in Ultrasound Biopsy \\
\hline Nurses & $3.12 \pm 0.53$ & \\
Nurse heads & $3.55 \pm 0.13$ & $0.0043^{*}$ \\
Nurse assistants & $1.54 \pm 0.45$ & \\
Physicians & $3.77 \pm 0.24$ & \\
\hline Practices of Patient Safety in Ultrasound Biopsy \\
\hline Nurses & $2.45 \pm 0.55$ & \\
Nurse heads & $1.22 \pm 0.94$ & $0.0012^{*}$ \\
Nurse assistants & $1.05 \pm 0.24$ & \\
Physicians & $3.24 \pm 0.53$ & \\
\hline$* 0<0.05$ &
\end{tabular}

dered infection prevention (mean \pm SD $=3.25 \pm$ 0.144 ) to be the most important aspect of patient safety in phlebotomy, whereas, the site dressing (mean $\pm \mathrm{SD}=3.55 \pm 0.646)$ after phlebotomy $\pm \mathrm{SD}=3.21 \pm 0.856)$ and wearing gloves and masks (mean $\pm \mathrm{SD}=3.55 \pm 0.521$ ) were considered as most important aspect and practice by respondents respectively.

The table-IV shows correlation of variables with participant groups. It is evident that awareness $(<0.001)$ and practices $(<0.001)$ of patient safety in phlebotomy have significant difference with respect to participant groups. On the other hand, awareness $(p=0.0043)$ and practices $(p=$ 0.0012) of patient safety in ultrasound biopsy also have significant difference.

In table- $\mathrm{V}$, demographics of participants have been correlated with variables of awareness and practices of patient safety in phlebotomy and ultrasound biopsy. The findings of study indicate that awareness and practices of patient safety in phlebotomy and ultrasound biopsy are associated with age, education and years of education.

\section{DISCUSSION}

Patient safety has remained important area of research for the previous many years ${ }^{11}$. Owing to its importance, extensive exploration has been directed towards understanding and implementation of patient safety ${ }^{12}$. However, most of the research has remained confined towards investigating patient safety generally. Moreover, patient safety in the aspects of ultrasound biopsy and phlebotomy has remained ignored ${ }^{13}$. Thus, the present study opted to highlight implementation

Table-V: Association of variables with demographics of participants.

\begin{tabular}{l|c|c|c|c}
\hline Demographics & $\begin{array}{c}\text { Awareness of } \\
\text { Patient Safety in } \\
\text { Phlebotomy }\end{array}$ & $\begin{array}{c}\text { Practices of Patient } \\
\text { Safety in } \\
\text { Phlebotomy }\end{array}$ & $\begin{array}{c}\text { Awareness of } \\
\text { Patient Safety in } \\
\text { Ultrasound Biopsy }\end{array}$ & $\begin{array}{c}\text { Practices of Patient } \\
\text { Safety in } \\
\text { Ultrasound Biopsy }\end{array}$ \\
\hline Age & $0.037^{*}$ & $0.019^{*}$ & $0.029^{*}$ & $0.038^{*}$ \\
\hline Gender & 0.285 & 0.476 & 0.184 & 0.374 \\
\hline Education & $0.046^{*}$ & $0.036^{*}$ & $0.002^{*}$ & $0.037^{*}$ \\
\hline Years of experience & $0.011^{*}$ & $0.047^{*}$ & $0.001^{*}$ & $0.033^{*}$ \\
\hline Work position & 0.374 & 0.376 & 0.284 & 0.572 \\
\hline Field & 0.184 & 0.742 & 0.174 & 0.474 \\
\hline
\end{tabular}

${ }^{*} p<0.05$

was most practiced feature of patient safety by participants.

In case of ultrasound biopsy, recognition and management of procedural complications (mean of patient safety in terms of phlebotomy and ultrasound biopsy.

Previous research works have tremendously indicated that health care workers lack in terms 
of knowledge regarding patient safety ${ }^{14}$. However, the findings of present research works shows that health care workers had adequate level of awareness and practice implementation of patient safety in both ultrasound biopsy and phlebotomy. This is in accordance with the research work of Sen et al ${ }^{10}$.

The selected aspects of patient safety showed statistically significant difference with respect to participant groups $(p \leq 0.05)$. Ahmed and $\mathrm{Ali}^{5}$ claimed that nurses highly lack in terms of patient safety skills of phlebotomy. The reason can be attributed to their improper basic education, inadequate in-service training and lack of orientation. However, the participant group of nurses and physicians showed higher level of awareness and practice implementation of patient safety for both aspects in present study. This is true with respect to research work of Brasaite et al ${ }^{1}$, which stated that lower awareness and practice of patient safety among other participant groups can be attributed to their lower position. Sometimes lower position has association with lower responsibility, which in this case results in lower implementation of patient safety practices ${ }^{15,16}$.

The awareness and practices of patient safety in phlebotomy and ultrasound biopsy were significantly associated with age, education and years of experience $(p \leq 0.05)$. The relation of years of experience with knowledge of patient safety has been highly advocated by the work of Flotta et alt. According to which, the number of years of experience has significant association with knowledge of evidence based patient safety procedures. Consequently, with more experience, knowledge level of physicians tends to increase. On the other hand, experienced health care workers become increasingly aware about failures in patient safety. The study of Brasaite et $a l^{1}$ and Hsaio et al ${ }^{6}$ emphasized that awareness and practices regarding patient safety enhances with education and experience level. However, the factor of education becomes a limitation after some time, whereas, the attribute of experience tends to increase continuously17,18.
The findings of present study emphasize on attributes of education and experience of health care workers. It implies the establishment of training programs and workshops to enhance awareness among health care workers regarding applicability of patient safety practices.

\section{CONCLUSION}

The present study is an effort towards understanding implementation of patient safety in two important fields of medicine including phlebotomy and ultrasound biopsy. The findings of present study suggest that overall the health care workers have adequate awareness and practice implementation of patient safety, which tend to increase with age, education and experience. However, the group of nurse assistants needs special attention and support from managers and co-workers to enhance their competence.

\section{CONFLICT OF INTEREST}

This study has no conflict of interest to declare by any author.

\section{REFERENCES}

1. Brasaite I, Kaunonen M, Martinkenas A, Mockiene V, Suominen T. Health Care Professionals' Knowledge Regarding Patient Safety. Clin Nurs Res 2016; 1(1): 1-16.

2. Ullman AJ, Long DA, Rickard CM. Prevention of central venous catheter infections: A survey of paediatric ICU nurses' knowledge and practice. Nurse Edu Today 2014; 34(1): 202-07.

3. Cicolini G, Simonetti V, Comparcini D, Labeau S, Blot S, Pelusi G, et al. Nurses' knowledge of evidence-based guidelines on the prevention of peripheral venous catheter-related infections: A multicentre survey. J Clin Nurs 2014; 23(1): 2578-88.

4. Flotta D, Rizza P, Bianco A, Pileggi C, Pavia M. Patient safety and medical errors: Knowledge, attitudes and behavior among Italian hospital physicians. Int J Qual Health Care 2012; 24(3): 258-65.

5. Ahmed HAM, Ali LMG. Best Practices Nursing Guideline in Phlebotomy for Patient Safety and Quality Improvement. J Nurs Health Sci 2016; 5(4): 1-16.

6. Hsaio GY, Chen IJ, Yu S, Wei IL, Fang YY, Tang FI. Nurses' knowledge of high-alert medications: Instrument development and validation. J Adv Nurs 2010; 66(1): 177-90.

7. Brasaite I, Kaunonen M, Suominen T. Healthcare professionals' knowledge, attitudes and skills regarding patient safety: a systematic literature review. Scand J Caring Sci 2015; 29(1): 30-50.

8. Comunale M, Sandoval M, Broussard T. An assessment of basic patient safety skills in residents entering the of clinical training. J Patient Saf 2015; 1(1): 1-5.

9. Merrill K. Leadership style and patient safety: implications for nurse managers. J Nurs Adm 2015; 45(6): 319-24.

10. Sen M, Azzani MMA, Rezaei A, Sen PK. A study to determine patient safety awareness and attitudes among medical students in a Malaysian University. Ind J Medical Sci 2019; 71(2): 66-81. 
11. Sartoretti T, Sartoretti E, Bucher C, Doert A, Binkert C, Hergan $\mathrm{K}$, et al. Bacterial contamination of ultrasound probes in different radiological institutions before and after specific hygiene training: do we have a general hygienical problem?. Eur Radiol 2017; 27(10): 4181-87.

12. Nyhsen C, Humphreys H, Nicolau C, Mostbeck G, Claudon M. Infection prevention and ultrasound probe decontamination practices in Europe: a survey of the European society of radiology. Insights Imag 2016; 7(6): 841-47.

13. Westerway $S$, Basseal J. The ultrasound unit and infection control - are we on the right track? Ultrasound 2017; 25(1): 53-57.

14. Ejtehadi F, Ejtehadi F, Teb J, MM A. A safe and practical decontamination method to reduce the risk of bacterial colonization of ultrasound transducers. J Clin Ultrasound 2014; 42(7): 395-98.
15. Westerway S, Basseal J, Brockway A, Hyett J, Carter D. Potential risks associated with an ultrasound examination - a bacterial perspective. J Ultrasound Med Biol 2016; 43(2): 421-26.

16. Just S, Humby F, Lindegaard H. Patient reported outcomes and safety in patients undergoing synovial biopsy: comparison of ultrasound-guided needle biopsy, ultrasound-guided portal and forceps and arthroscopic-guided synovial biopsy techniques in five centres across Europe. RMD Open 2018; 4(1): e000799.

17. Humby F, Kelly S, Bugatti S. Evaluation of minimally invasive, ultrasound-guided synovial biopsy techniques by the omeract filter-determining validation requirements. J Rheumatol 2016; 43(1): 208-13.

18. Nelson E, Eftimovska E, Lind C. Patient reported outcome measures in practice. Bio Med J 2015; 350(1): g7818. 